\title{
ALIH TEKNOLOGI PENGELOLAAN LIMBAH TERNAK BAGI UMKM MIKRO PETERNAK SAPI
}

\author{
Srie Juli Rachmawatie, Riana Rachmawati Dewi, Tria Rosana Dewi \\ Universitas Islam Batik Surakarta, Jl. Agus Salim No.10, Sondakan, Laweyan, Kota Surakarta, \\ Jawa Tengah 57147, Indonesia \\ Email: sriejulirachmawatie@gmail.com
}

\begin{abstract}
ABSTRAK
Masih banyaknya peternak sapi di desa Mayang yang belum memahami pentingnya alih teknologi untuk mengelola limbah ternak yang berbentuk padat dan cair. Hal ini seharusnya mulai dipikirkan mengingat lokasi usaha berada didaerah yang padat penduduk. Limbah ternak yang berbentuk cair masih secara sederhana di pagi hari diambil untuk dijadikan pestisida, tetapi yang padat hanya dibuang dibelakang lokasi kandang. Pengolahan limbah menjadi penting karena dapat memberikan manfaat bagi mitra terutama dan masyarakat di sekitarnya. Alih teknologi dengan degester dijadikan salah satu solusi alternatif termasuk limbah biogasnya. Pelatihan pemanfaatan teknologi dan pengelolaan dampaknya dilakukan agar masyarakat memahami pentingnya menggunakan fasilitas teknologi di era sekarang. Akhirnya mitra dapat menikmati manfaat yang diberikan dalam mengelola limbah yaitu biogas untuk industri rumah tangga dan pengelolaan keuangan. Kandang yang sudah diperbaiki dapat digunakan secara efektif dan efisien karena limbahnya masuk ke instalasi degester tanpa perlu dibersihkan secara tradisional dan menghemat biaya perawatan kandang.
\end{abstract}

Kata kunci: edukasi, pemanfaatan limbah, alih teknologi

\begin{abstract}
There are still many cattle farmers in the village of Mayang who do not understand the importance of technology transfer to manage livestock waste in the form of solid and liquid. This should begin to be considered given the business location is in a densely populated area. Livestock waste in the form of liquid is still simply taken in the morning to be used as a pesticide, but the solid one is only thrown behind the cage location. Waste treatment is important because it can provide benefits for partners especially and surrounding communities. Technology transfer with degester is used as an alternative solution including biogas waste. Training on technology utilization and impact management is done so that people understand the importance of using technology facilities in the current era. Finally partners can enjoy the benefits provided in managing waste, namely biogas for the home industry and financial management. The repaired enclosure can be used effectively and efficiently because the waste enters
\end{abstract}


the degester installation without needing to be cleaned traditionally and saves maintenance costs.

Keywords: education, utilization of waste, transfer of technology

\section{PENDAHULUAN}

Salah satu program peternakan yang dilaksanakan didesa Mayang yaitu pengembangbiakan hewan ternak. Hewan ternak yang banyak dijumpai di desa Mayang adalah sapi dan kambing. Kami bekerjasama dengan 2 (dua) mitra yang produktif secara ekonomi, yaitu peternak. Mitra pertama Bapak Heru Wiyono adalah peternak sapi yang mempunyai rumah berdekatan dengan warung makan, sedangkan mitra kami Bapak Tri Harsono selain peternak sapi juga pemilik lahan rumput gajah. Mitra pertama selalu memanfaatkan rumput gajah milik mitra kedua. Lokasi kedua mitra berjarak $\pm 100 \mathrm{~m}$ sehingga berdekatan. Kedua mitra rata-rata memiliki ternak sapi $4-5$ ekor dan dirawat secara pribadi dan limbah ternak dibuang dibelakang rumah dan merupakan halaman kosong. Kedua mitra berada pada lingkungan yang sama yaitu RT 1 RW 1 desa Mayang Kecamatan Gatak Kabupaten Sukoharjo. Kedua mitra mengeluhkan kotoran sapi yang setiap harinya berkisar $25 \mathrm{~kg}$ (berat kotor) harus dibersihkan. Kotoran sapi akan dibiarkan kering dan dimanfaatkan sebagai pupuk kandang. Kotoran sapi yang dibiarkan kering dengan berat $8 \mathrm{~kg}$ menimbulkan bau yang kurang sedap dan banyak dihinggapi lalat.

Pola pengolahan limbah sapi yang masih sederhana dan belum dimanfaatkan secara optimal dalam bentuk pupuk kandang masih menjadi salah satu alternatif solusi bagi masyarakat di lingkungan desa Mayang Kecamatan Gatak Kabupaten Sukoharjo. Dampak ekonomi belum kelihatan optimal dalam mengelola pupuk kandang kecuali apabila sapi yang dipelihara dijual maka dapat menghasilkan uang. Masyarakat juga kesulitan mengakses kredit perbankan untuk kredit produktif karena belum mempunyai tata kelola keuangan meskipun sederhana.

Biaya memelihara ternak sapi memang masih tergolong mahal karena membutuhkan kebersihan tempat setiap harinya. Pentingnya perbaikan pengelolaan limbah ternak sehingga menjadi hal yang produktif dan dapat memberikan nilai tambah bagi sekitarnya Limbah sapi dapat dimanfaatkan untuk keperluan rumah tangga dalam bentuk biogas bagi warung makan sekitarnya dilokasi \pm 25 meter. Limbah yang berupa kotoran sapi dibiarkan menumbuk di samping kandang atau dibelakang rumah dan dibiarkan mengering termasuk rumput gajah yang masih sisa pakan. Pengolahan limbah yang masih sederhana dengan ditumpuk dan dijadikan pupuk kandang ternyata sering dihinggapi oleh lalat dan binatang kecil lain yang dapat membahayakan bagi lingkungan. Diperlukan suatu teknologi untuk mengolah limbah yang memungkinkan memberikan nilai tambah bagi lingkungan 


\begin{abstract}
sekitanya dan pelatihan pemanfaatannya. Perbaikan kandang ternak diperlukan untuk memudahkan peternak dalam membersihkan dan mengelola limbah tersebut ke tempat pembuangan akhir.
\end{abstract}

Kedua mitra mempunyai usaha yang sejenis yaitu peternak, untuk usaha tersebut rata-rata kedua mitra membeli anak sapi seharga \pm 13 juta untuk kemudian dipelihara \pm 1 tahun kemudian dijual seharga dua kali lipatnya. Penjualan dilakukan di pasar ternak atau pembeli langsung ke rumah mitra. Mitra juga memelihara sapi yang sudah dewasa untuk kemudian dijual kembali. Mitra hanya mengandalkan insting atau naluri karena kebiasaan dan pengalaman dalam memelihara dan menjual hewan ternaknya. Tidak jarang antara biaya pemeliharaan dan penjualan meskipun laba tetapi dianggap tidak menutup biaya yang sudah dikeluarkan meskipun perhitungan itu belum pernah dilakukan secara terperinci.

Rencana program ipteks bagi masyarakat ini diprioritaskan pada sektor peternakan dan pertanian. Sudah terdapat pengusaha mikro peternak sapi dan pertanian serta industri warung makan. Pada Program Kemitraan Masyarakat (PKM) ini melibatkan 2 (dua) mitra pengusaha mikro yaitu peternak sapi pertama bernama Heru Wiyono dan peternak sapi kedua sekaligus pemilik kebun rumput gajah bernama Tri Harsono. Permasalahan yang dihadapi kedua pengusaha tersebut berdasarkan dari survey yang dilakukan dirinci sebagai berikut: (1)
Permasalahan Aspek Produksi dimana kandang sapi yang masih tradisional menyulitkan untuk dibersihkan sehingga dapat memperpanjang waktu untuk membersihkan limbah dan menguras tenaga, limbah yang dtumpuk di belakang dan samping kandang menambah masalah lingkungan, rumput gajah sebagai pakan ternak biasanya tidak habis dan juga dapat menjadi masalah tersendiri, belum adanya teknologi yang dimanfaatkan di desa tersebut dalam mengelola limbah ternak. (2) Permasalahan manajemen yaitu manajemen pemeliharaan hewan ternak mitra masih terbatas pada insting dan pengalaman sehingga belum ada pembukuan yang dapat menjelaskan untung dan rugi yang didapatkan, manajemen pemeliharaan masih mengandalkan tenaga sendiri dan keluarga untuk memlihara hewan ternak sehingga dianggap bukan sebagai pengeluaran biaya, peternak belum terbiasa membuat pengelolaan keuangan karena dianggap terlalu repot dan tidak memberikan manfaat.

\section{METODE}

Metode yang dilakukan untuk menjawab salah satu masalah yang dikemukakan diatas yaitu:

1. Penguasaan pemakaian teknologi Dengan membuat mesin degester yaitu mengolah limbah sapi (kotoran dan urin) menjadi biogas. Tim membuatkan alat pengolah (degester) dan selanjutnya memberikan pelatihan pemanfaatan pemakaian degester dan biogas untuk bahan bakar kompor dalam rumah tangga 
mitra. Tetangga mitra yang juga seorang wirausaha warung makan diberikan juga alih teknologi biogas mengingat lokasi mitra Bapak Heru Wiyono dan Warung Bu Harni.

2. Kemampuan mengelola limbah Adanya limbah biogas yang berbentuk cair dan padat (slury) dapat dimanfaatkan menjadi pupuk untuk tanaman mitra yang satunya Bapak Tri Harsono.

3. Peningkatan manajemen usaha Perbaikan kandang ternak dilakukan untuk mendapatkan kandang yang langsung dihubungkan dengan degester. Bentuk kandang dibuat agak miring untuk memudahkan melancarkan kotoran dan urin ke dalam alat pengolah. Pelatihan dilakuakn setelah adanya perbaikan kandang agar dapat menghitung besarnya dana yang digunakan dan realisasi penjualan

Semua hal untuk perbaikan kandang, pembuatan degetser, pengolahan limbah biogas sudah mulai dilaksanakan pada bulan Agustus 2018. Sosialisasi dan pelatihan dilakukan setelah degetser dan kandang sudah ada. Pembuatan degester dilakukan dibelakang kandang sapi karena di tempat tersebut milik mitra Bapak Heru Wiyono masih luas dan sebagai tempat pembuangan kotoran sapi yang tidak terpakai sebelumnya. Degetser dan pembuanagn yang dibuat diberi pembatas agar tidak dijadikan loaksi permainan anakanak mengingat lokasi tersebut di wilayah pemukiman Desa Mayang
Kecamatan Gatak Kabupaten Sukoharjo yang padat penduduknya. Rivai dan Basri (2005) menjelaskan pelatihan adalah proses sistematis untuk mengubah tingkah laku pegawai untuk mncapai tujuan organisasi. Pelatihan berkaitan dengan keahlian dan kemampuan pegawai untuk melaksnakan pekerjaan saat ini. Pelatihan memiliki orientasi saat ini dan membantu pegawai untuk mencapai keahlian dan kemampuan tertentu agar berhasil dalam melaksanakan pekerjaannya. Siagian dalam Lubis (2008) mendefinisikan pelatihan sebagai proses belajar mengajar dengan menggunakan teknik dan metode tertentu secra konsepsional dapat dikatakan bahwa seseorang atau sekelompok orang biasanya yang biasanya sudah bekerja pada suatu organisasi yang efisiensi, efektivitas dan produktivitas kerjanya dirasakan perlu untuk dapat ditingkatkan secara terarah dan pragmatik.

Tahapan dalam proses pelatihan meliputi perencanaan, pelaksanaan, evaluasi dan analisis hasil yang sudah dilakukan. Masing-masing tahapan melibatkan mitra dan tetangga sekitar dan pemilik usaha warung makan yang juga merupakan menjadi sasaran PKM. Selama melakukan tahapan proses pelatihan, tim dan mitra melakukan studi banding dan pelatihan ke tenaga Ahli Bapak Ir. Gembong Danudiningrat di Yogyakarta. 


\section{HASIL DAN PEMBAHASAN}

Perbaikan kandang ternak dan pembuatan instalasi biogas sudah selesai dilakukan pada tanggal 13 Agustus 2018. Waktu yang dibutuhkan untuk perbaikan kandang adalah 8 hari efektif dan dimulai dari 25 Juli sd 2 Agustus 2018, sedangkan untuk pembuatan instalasi degester selama 7 hari dimulai dari 3 sd. 9 Agustus 2018. Pada tanggal 11 Agustus 2018, tim dan mitra melakukan serah terima alat (kandang yang sudah diperbaiki dan instalasi biogas) selanjutnya dilakukan pelatihan pemanfaatan dan pengolahan biogas. Uji coba kompor biogas dan instalasi untuk mitra dan pemilik warung makan.
Tanggal 18 Agustus 2018 tim dan salah satu mitra ke lokasi Tenaga Ahli di Yogyakarta. Tenaga ahli yang dikunjungi mempunyai tempat penelitian untuk pertanian dan peternakan. Di tempat tersebut diberikan pemahaman dalam mengelola kotoran ternak dan sisa pakan, pemnafaatan pupuk organik untuk perikanan, juga teknologi pertanian yang dikembangkan. Tim dan mitra melakukan pelatihan pembuatan pupuk organik dan pengolahan lahan serta pakan ikan. Praktek di lokasi secara langsung memberikan pengalaman yang berbeda.

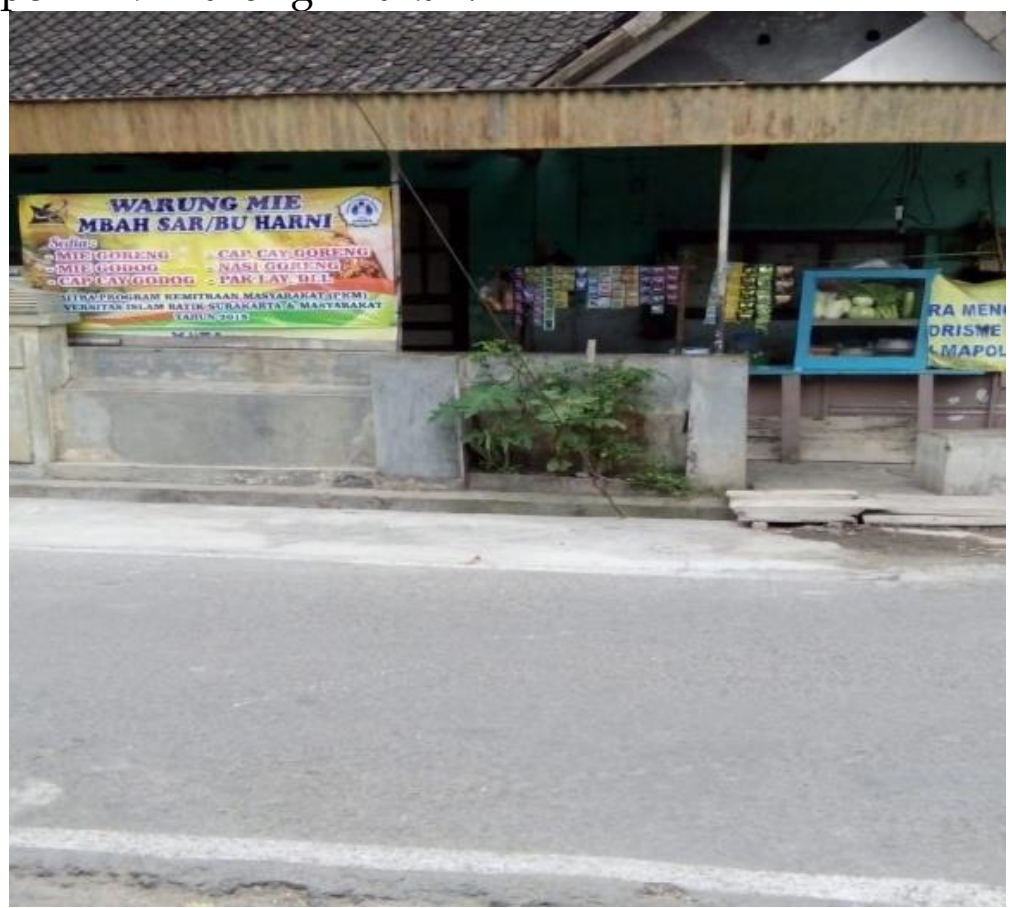

Gambar 1. Warung makan mitra 


\begin{tabular}{rrr} 
ISSN & $: 1979-861 X$ \\
e-ISSN & $: 2549-1555$ \\
\hline \hline
\end{tabular}

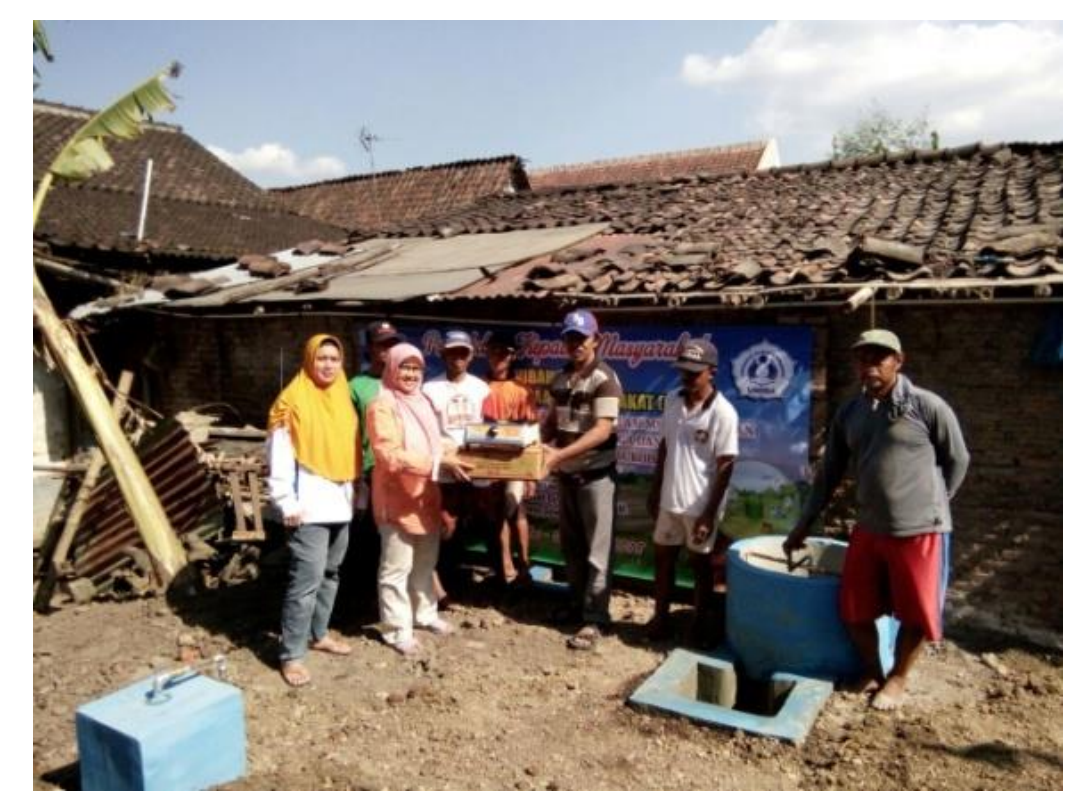

Gambar 2. Instalasi Biogas dan Kompor

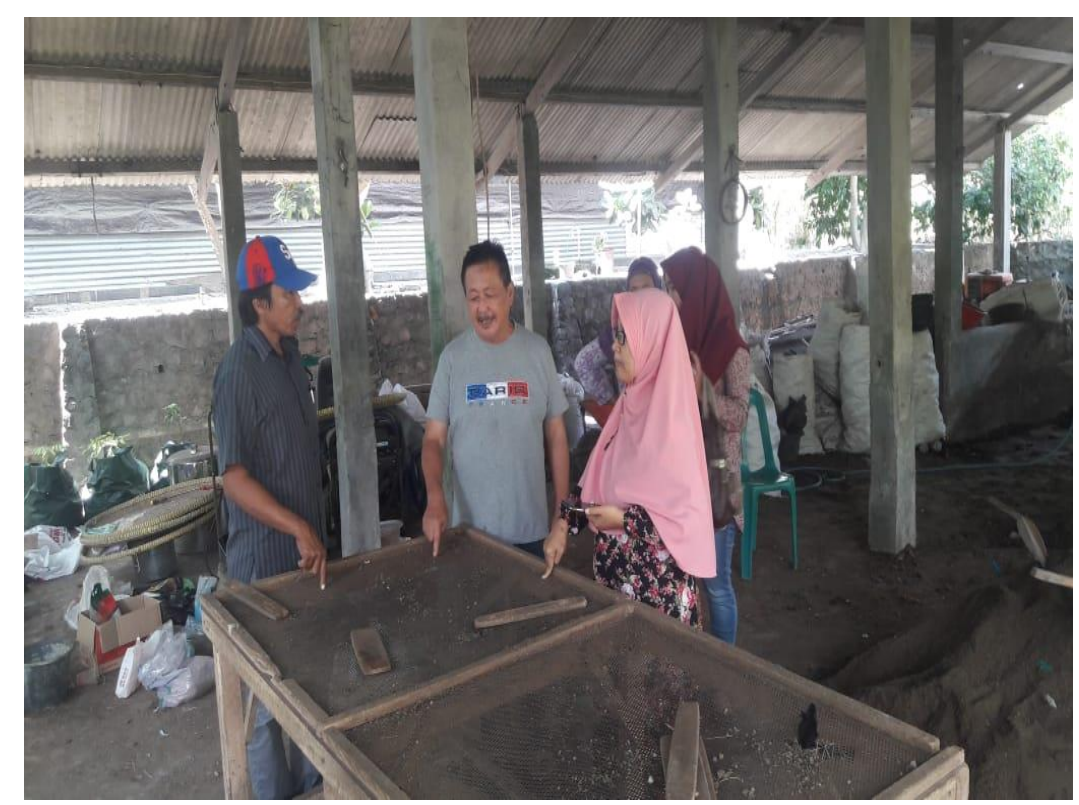

Gambar 3. Pembelajaran ke Tenaga Ahli untuk pembuatan pupuk organik

Memberikan alih teknologi dianggap cukup untuk skala industri untuk peternak dan masyarakat rumah tangga. Bahan baku yang umum berupa peralatan biogas dibutuhkan sebanyak $25 \mathrm{~kg}$ kotoran membutuhkan biaya pribadi yang sapi ( untuk 2 ekor sapi) per harinya. dikeluarkan dan cukup mahal. Lokasi Produksi 3 hari biogas setara dengan pemanfaatan biogas maksimal di area 1 gas elpiji $3 \mathrm{~kg}$. Artinya 1 tabung $\pm 20 \mathrm{~m}^{2}$. Ukuran degester sebesar 8 yang berisi gas elpiji $3 \mathrm{~kg}$ dihargai kubik cukup untuk 2 kompor bagi Rp. 19.000,- sehingga terdapat rumah tangga dan menyala setiap penghematan pemakaian elpiji harinya 8 jam yaitu 4 jam pagi dan 4 selama 1 bulan (30 hari) yaitu Rp. jam di sore hari. Hal tersebut $19.000 \times 10$ buah $=$ Rp. 190.000,- dan 
secara tidak langsung dapat mengurangi polusi lingkungan berupa pemanfaatan limbah kotoran sapi. Pemanfaatan limbah sapi dalam bentuk pupuk kandang baru uji coba di awal September dan belum teruji hasilnya.

\section{KESIMPULAN}

Pelaksanaan kegiatan pengabdian kepada masyarakat yang berjudul "PKM Pengusaha Mikro Peternak Sapi dalam Memanfaatkan Limbah Ternak untuk Gas Rumah Tangga dan Pertanian di Desa Mayang Kecamatan Gatak Kabupaten Sukoharjo" telah dilaksanakan sesuai rencana. Secara garis besar, mitra dan tetangga sekitar mitra menyambut gembira karena kegiatan ini dianggap dapat memberikan manfaat yang positif dan dapat memberikan dampak yang baik karena selain memberikan gambaran alih teknologi juga mendapatkan praktek dan adanya pelatihan dalam bentuk nyata yang dikembangkan di Desa Mayang Kecamatan Gatak Kabupaten Sukoharjo.

\section{DAFTAR PUSTAKA}

Andhina P H. 2015. Pengelolaan Limbah Ternak Sapi menjadi Biogas. Majalah Ilmiah Pawiyatan Volume XXII no.1

Buku Panduan Pelaksanaan Penelitian dan Pengabdian kepada Masyarakat Edisi XI tahun 2017.

Chandra A. 2017. Produksi Biogas dari Campuran Kotoran Sapi dan Rumput Gajah. Skripsi Fakultas Pertanian Universitas Lampung
Lubis K A. 2008. Pengaruh Pelatihan dan Motivasi Kerja terhadap Kinerja Karyawan PT. Perkebunan Nusantara IV (Persero) Medan. Respitory.usu.ac.id. Medan.

Rivai V, Basri A F M. 2005. Performance Appraisal: Sistem yang tepat guna untuk menilai kinerja karyawan dan meningkatkan daya saing perusahaan. Jakarta: PT. Raja Grafindo Persada

Wedo S. 2010. Produksi Biogas dari Biomassa Kotoran Sapi dalam Biodigester Fix Dome dengan Pengenceran dan Penambahan Agitasi. 